\title{
SACARIFICAÇÃO DA SERRAGEM DE BAMBU VISANDO AO ESTABELECIMENTO DE UM MÉTODO DE DETERMINAÇÃO DE AMIDO (1)
}

\author{
ANISIO AZZINI $(2,4)$ e MARIA CARLA QUEIROZ ARRUDA (3)
}

\begin{abstract}
RESUMO
No presente estudo, determinaram-se as condiçốes de hidrólise da serragem de colmo de bambu (Bambusa vulgaris Schrad.), visando ao estabelecimento de um método de determinação de amido. Os resultados obtidos mostram que as condiçōes mais adequadas de sacarificação de amido na serragem foram obtidas em solução de ácido sulfúrico na concentração de $2 \%$ (v/v), ap6s 60 minutos de reação sob refluxo, empregando-se uma relação de 1:30, entre a quantidade de serragem e o volume da solução. Nessas condiçöes, o teor de amido no colmo (A) foi calculado em função do rendimento em glicose proveniente da hidrólise do amido (Gh), do teor de glicose na serragem $(\mathrm{Ga})$ e do fator de conversão de glicose para amido $(0,9)$, através da seguinte expressão: $A=(\mathrm{Gh}-\mathrm{Ga})$ x 0,9 .
\end{abstract}

Termos de indexação: bambu, amido, método de determinação, sacarificaçăo.

\section{INTRODUÇÃO}

Nos últimos anos, tem-se observado uma crescente demanda por connecimentos científicos e tecnológicos, específicos para o bambu, visando a sua

(1) Recebido para publicação em 6 de novembro de 1984.

(2) Seção de Plantas Fỉbrosas, Instituto Agronómico (IAC), Caixa Postal 28, 13001 Campinas (SP).

(3) Estagiária da Seçāo de Plantas Fibrosas, IAC.

(4) Com bolsa de suplementação do CNPq. 
utilização como matéria-prima celulósica e energética. Neste particular, os recentes trabalhos de pesquisa desenvolvidos conjuntamente pelo Instituto Agronômico e Instituto de Tecnologia de Alimentos (AZZINI, 1981, 1983a, 1983b, 1984, MENEZES \& AZZINI, 1981, e MENEZES et alii, 1983), têm ressaltado as grandes possibilidades tecnológicas do bambu para produção de celulose, amido, álcool e alimento (broto de bambu).

De acordo com a constituição física, química e anatômica do colmo de bambu, o processamento tecnológico mais racional para essa matéria-prima fibrosa é aquele que visa à produção conjunta de celulose/amido ou celulose/etanol. Entretanto, para atingir esse objetivo, há necessidade de desenvolver conhecimentos tecnológicos específicos, principalmente com relação às condições de hidrólise ou sacarificação do amido.

O objetivo deste estudo foi determinar as condições de hidrólise do amido de bambu e estabelecer um método de sua determinação no colmo, transformado em serragem.

\section{MATERIAL E MÉTODO}

O material empregado neste estudo - amido e serragem - foi obtido a partir de colmos de Bambusa vulgaris Schrad., com dois anos de idade, provenientes da coleção de espécies localizada no Centro Experimental de Campinas.

\section{Extração e sacarificação do amido}

Após a extração do amido, conforme procedimento desenvolvido por AZZINI (1983b), estabeleceram-se as condiçōes de sua hidrólise em meio ácido. Para tanto, empregaram-se diferentes soluçōes de ácido sulfúrico, com relação à concentração $(0,5,1,0,1,5$ e 2,0\% base $v / v)$ e tempo de reação sob refluxo em chapa de aquecimento (30,60, 90 e 120 minutos). A quantidade de amido a ser hidrolisada nas diferentes condiçōes estudadas foi de $0,5 \mathrm{~g}$ (base seca), dissolvida em $50 \mathrm{ml}$ de solução. Os açúcares aldeídicos obtidos após a hidrólise do amido foram dosados conforme procedimento analítico empregado por AZZINI \& QUEIROZ (1984).

\section{Sacarificação do amido na serragem}

A serragem, com granulometria de 40 "mesh", foi obtida na região mediana do colmo de bambu, considerando dois internódios consecutivos. Para estabelecer as condições mais adequadas de hidrólise do amido na serragem, determinou-se o efeito do volume da solução $(100,150 \mathrm{e} 200 \mathrm{ml})$ na presença e na ausência da desintegraçáo das amostras em liquidificador, bem como os efeitos da temperatura da solução $\left(25,40\right.$ e $\left.80^{\circ} \mathrm{C}\right)$, durante a desintegração das amostras e o tempo de reação sob refluxo.

As condições de hidrólise ou sacarificação, com relação à concentração da solução de ácido sulfúrico, tempo de reação, volume e temperatura da solução durante a desintegração da amostra em liquidificador, foram determinadas, esta- 
belecendo-se assim uma metodologia para dosar o amido no colmo de bambu transformado em serragem. O teor de glicose presente na serragem de bambu antes da hidrólise foi determinado como uma prova em branco na ausência da solução de ácido sulfúrico.

\section{RESULTADOS E DISCUSSĀO}

Os resultados da hidrólise ácida do amido extraído de colmos de Bambusa vulgaris Schrad., em função da concentração do ácido sulfúrico e do tempo de reaçāo sob refluxo, são apresentados no quadro 1 . Esses dados revelam que o amido de bambu foi totalmente hidrolisado em solução a $2 \%$ de ácido sulfúrico, após 60 minutos de reação, quando os valores para o rendimento em glicose estabilizaram-se próximo de $94 \%$. Fixando-se essas condições de sacarificação para o amido, com relaçāo à concentraçāo da soluçāo $(2 \%)$ e tempo de reação $\{60$ minutos), a etapa seguinte foi determinar algumas variáveis da hidrólise, empregando-se a serragem de bambu.

Nos quadros 2, 3 e 4, são apresentados os rendimentos de sacarificação da serragem em função do volume da solução, da desintegração da amostra em liquidificador, da temperatura da solução durante a desintegração e do tempo de reação sob refluxo.

Pelo quadro 2, a temperatura da solução durante a desintegração das amostras não influiu no rendimento em glicose. Os resultados obtidos variaram de 20,4 a $20,7 \%$, respectivamente, para as temperaturas de 25 a $80^{\circ} \mathrm{C}$. Quando a hidrólise da serragem se processou em diferentes volumes de solução $(100,150 \mathrm{e}$ $200 \mathrm{ml}$ ), os resultados - Quadro 3 - salientam que o maior rendimento de sacarificaçāo $(26,10 \%)$ foi obtido quando se empregou uma relação de 1:30, entre a quantidade de serragem $(5,0 \mathrm{~g})$ e o volume da solução $(150 \mathrm{ml})$. A análise estatística não acusou efeito significativo da desintegração das amostras em liquidificador. No quadro 4 , os dados evidenciam que o tempo de reação sob refluxo influiu na hidrólise da serragem, mostrando que o menor tempo (30 minutos) não foi suficiente para uma completa sacarificação do amido. Os rendimentos máximos obtidos nos tempos de 60,90 e 120 minutos $(26,10,27,90$ e $27,90 \%$ respectivamente) não apresentaram diferenças estatísticas entre si.

O teor de amido no colmo de bambu transformado em serragem foi calculado em função do rendimento em glicose proveniente da sacarificação do amido e do teor de glicose na serragem - Quadro 5 - através da seguinte expressão:

$$
A=(G h-G a) \times 0,9
$$

onde:

$A=$ Teor de amido na serragem, expresso em porcentagem (base seca);

$\mathrm{Gh}=$ Rendimento em glicose proveniente da sacarificação do amido, expresso em porcentagem (base seca); 
$\mathrm{Ga}=$ Teor de glicose na serragem de bambu, expresso em porcentagem (base seca);

0,9 = Fator de conversão de glicose para amido.

Pelo procedimento indicado e considerando-se o teor médio de glicose na serragem (1,51\%) - Quadro 5 - o teor de amido no colmo de Bambusa vulgaris Schrad., ora em estudo, foi de $22,13 \%(\mathrm{~m} / \mathrm{m})$.

QUADRO 1. Rendimento em glicose, após a hidrólise ácida do amido de bambu, em funçāo da concentração da soluçãoe do tempo de reação, sob refluxo. Médias de três repetições $\left({ }^{1}\right)$

\begin{tabular}{ccc}
$\begin{array}{c}\text { Concentraçāo da } \\
\text { solução de } \\
\mathrm{H}_{2} \mathrm{SO}_{4}\end{array}$ & $\begin{array}{c}\text { Tempo de } \\
\text { hidrólise }\end{array}$ & $\begin{array}{c}\text { Rendimento em glicose } \\
\text { sobre o peso seco } \\
\text { de amido }\end{array}$ \\
\hline
\end{tabular}

\begin{tabular}{lrr}
$\%(\mathrm{v} / \mathrm{v})$ & $\min$ & $\%(\mathrm{~m} / \mathrm{m})$ \\
0,5 & 30 & $21,45 \mathrm{j}$ \\
& 60 & $40,05 \mathrm{~h}$ \\
& 90 & $54,75 \mathrm{f}$ \\
& 120 & $65,25 \mathrm{e}$ \\
\hline
\end{tabular}

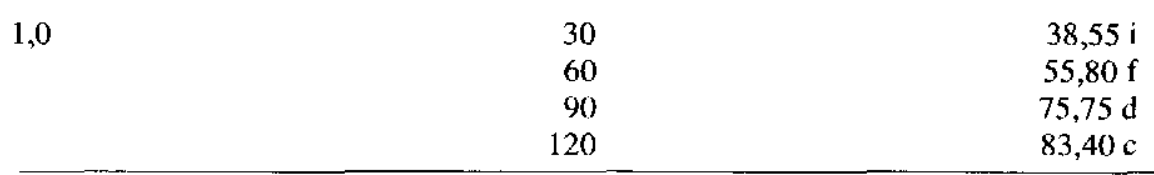

\begin{tabular}{rrr}
30 & 60 & $46,80 \mathrm{~g}$ \\
& 90 & $78,60 \mathrm{~d}$ \\
& 90 & $85,95 \mathrm{bc}$ \\
& 120 & $89,40 \mathrm{ab}$ \\
\hline & & \\
& 30 & $61,80 \mathrm{e}$ \\
& 60 & $94,05 \mathrm{a}$ \\
& 90 & $93,75 \mathrm{a}$ \\
& 120 & $91,65 \mathrm{a}$
\end{tabular}

(1) Teste F: Conc. da soluçăo 
QUADRO 2. Rendimento em glicose após a hidrólise da serragem de bambu, em função da temperatura da solução durante a desintegração da amostra em liquidificador. Média de três repetições

\begin{tabular}{lc}
$\begin{array}{c}\text { Temperatura } \\
\text { da } \\
\text { solução ácida }\end{array}$ & $\begin{array}{c}\text { Rendimento em glicose } \\
\text { sobre o peso seco } \\
\text { de serragem }\left(^{1}\right)\end{array}$ \\
\hline oC & $\%(\mathrm{~m} / \mathrm{m})$ \\
25 & 20,4 \\
40 & 20,4 \\
80 & 20,7 \\
\hline Teste F & $0,09 \mathrm{M} . \mathrm{S}$. \\
C.V. $(\%)$ & 4,85 \\
\hline
\end{tabular}

(1) Condiçōes de hidrólise: conc. da sol. de $\mathrm{H}_{2} \mathrm{SO}_{4}=2,01 \%$ (v/v); relaçäo entre a quantidade de serragem e o volume da solução $=1 / 20$; tempo de reação $=60$ minutos; tempo de desintegraçăo da amostra em liquidificador $=30$ segundos.

QUADRO 3. Rendimento em glicose após a hidrólise da serragem de bambu, em função do volume da solução hidrolisante e da desintegraçāo da amostra. Médias de três repetiçōes

\begin{tabular}{lcc}
\hline $\begin{array}{c}\text { Vol. da } \\
\text { solução }\end{array}$ & $\begin{array}{c}\text { Desintegração } \\
\text { da amostra }\end{array}$ & $\begin{array}{c}\text { Rendimento em glicose } \\
\text { sobre o peso seco } \\
\text { de serragem (1) }\end{array}$ \\
\hline $\begin{array}{c}\text { Com liquidificador } \\
100\end{array}$ & Sem liquidificador & $19,80 \mathrm{~b}$ \\
\hline 150 & Com liquidificador & $20,40 \mathrm{~b}$ \\
\hline 200 & Sem liquidificador & $26,10 \mathrm{a}$ \\
\hline Teste F & Com liquidificador & $24,75 \mathrm{a}$ \\
Tukey $(5,0 \%)$ & Sem liquidificador & $25,20 \mathrm{a}$ \\
C.V. $(\%)$ & - & $24,00 \mathrm{a}$ \\
\hline
\end{tabular}

(1) Condiçōes de hidrólise: conc. da sol. de $\mathrm{H}_{2} \mathrm{SO}_{4}=2,0 \%$ (v/v); serragem $=5,0 \mathrm{~g}$ (base seca); tempo de reação = 60 minutos; tempo de desintegração da amostra em liquidificador $=30$ segundos. 
QUADRO 4. Rendimento em glicose após a hidrólise da serragem de bambu, em função do tempo de reação sob refluxo. Médias de três repetições

\section{Tempo de reação}

\section{Rendimento em glicose} sobre o peso seco de serragem $\left({ }^{1}\right)$

\begin{tabular}{lc}
\hline $\min$ & $\%(\mathrm{~m} / \mathrm{m})$ \\
30 & $20,25 \mathrm{~b}$ \\
60 & $26,10 \mathrm{a}$ \\
90 & $27,90 \mathrm{a}$ \\
120 & $27,90 \mathrm{a}$ \\
\hline Teste F & $24,64^{* *}$ \\
Tukey $(5 \%)$ & 3,53 \\
C.V. $(\%)$ & 5,28 \\
\hline
\end{tabular}

(1) Condiçōes de hidrólise: concentração da solução de $\mathrm{H}_{2} \mathrm{SO}_{4}=20 \%$ (v/v); relação entre a quantidade de serragem e o volume da solução $=1: 30$.

QUADRO 5. Teor de glicose na serragem de bambu $\left({ }^{1}\right)$

\begin{tabular}{lc}
\hline $\begin{array}{l}\text { Determi- } \\
\text { nações }\end{array}$ & $\begin{array}{c}\text { Teor de glicose } \\
\text { na serragem } \\
\text { (base seca) }\end{array}$ \\
\hline $\mathrm{n}^{\mathbf{0}}$ & $\%(\mathrm{~m} / \mathrm{m})$ \\
1 & 1,35 \\
2 & 1,62 \\
3 & 1,49 \\
4 & 1,62 \\
5 & 1,49 \\
6 & 1,49 \\
\hline Média & 1,51 \\
C.V. (\%) & 6,68 \\
\hline
\end{tabular}

(1) Condiçōes de determinação: relação entre a quantidade de serragem e o volume da solução $=1 / 30$; tempo de desintegração da amostra em liquidificador $=30$ segundos. 


\title{
4. CONCLUSÕES
}

Com a realização deste estudo, foi possivel tirar as seguintes conclusões:

1) O rendimento máximo em glicose proveniente da sacarificação do amido, obtido a partir da serragem de bambu, estabilizou-se próximo dos $60 \mathrm{mi}$ nutos de reação sob refluxo em solução de ácido sulfúrico com $2,0 \%$ de concentração;

2) A desintegraçāo da amostra em liquidificador, bem como as temperaturas da solução, durante a desintegração $\left(25,40\right.$ e $\left.80^{\circ} \mathrm{C}\right)$, não influíram no rendimento de sacarificação;

3) A relação 1:30, entre a quantidade de serragem e o volume da solução, foi a mais indicada para sacarificação do amido presente na serragem de bambu;

4) O procedimento analítico ora descrito representa um método alternativo simples e de fácil execução para deteminar o teor de amido em colmos de bambu.

\section{SUMMARY \\ SACCHARIFICATION OF BAMBOO SAWING FOR STARCH DETERMINATION}

\begin{abstract}
Saccharification conditions of bamboo sawing (Bambusa vulgaris Schrad.) were determined for the stablishment of an analytic method for starch determination in bamboo culm. The results showed that the best conditions for sawing saccharification were obtained with a $2.0 \%(\mathrm{v} / \mathrm{v})$ sulfuric acid solution after 60 minutes of reaction under heating, using the relationship 1:30 (w/v) between the quantity of bamboo sawing and the volume of the acid solution. In this conditions the starch content in the bamboo culm was calculated by the following expressions: $A=(\mathrm{Gh}-\mathrm{Ga}) \mathrm{x}$ 0.9, where: $\mathrm{A}=$ starch content in the bamboo sawing, expressed in percentage (oven dry); $\mathrm{Gh}=$ glucose yield, obtained from starch saccharification, expressed in percentage (oven dry); $\mathrm{Ga}=$ glucose content in the bamboo sawing, expressed in percentage (oven dry); $0.9=$ conversion factor from glucose to starch.
\end{abstract}

Index terms: bamboo, starch, method of determination, saccharification.

\section{REFERÊNCIAS BIBLIOGRÁFICAS}

AZZINI, A. Amido a partir do bambu. Bragantia, Campinas, 43(1):45-50, 1984.

Biomass from bamboo and its possible utilization in Brazil. In: INTERNATIONAL SYMPOSIUM ON UTILIZATION OF BIOMASS IN THE TROPICAL AREA, Okinawa, Japan, 1983a. p.153-166. 
AZZINI, A. Desfibramento de bambu visando à produçâo conjunta de celulose e amido. In: CONGRESSO LATINO-AMERICANO DE CELULOSE E PAPEL, 3., São Paulo, 1983b. p.229-248.

\& QUEIROZ, M.C. Método de determinação de açúcares aldeídicos a partir do amido de bambu. Bragantia, Campinas, 44(1):411-416, 1984.

SALGADO, A.L.B.; TEIXEIRA, J.P.F. \& MORAES, R.M. Obtenção de amido a partir do colmo de bambu. Bragantia, Campinas, 40:211-216, 1981.

MENEZES, T.V.B. \& AZZINI, A. Bambu, uma nova matéria-prima para produçāo de etanol. Boletim do ITAL, Campinas, 18:145-154, 1981.

; SANTOS, C.L.M. \& AZZINI, A. Saccharification of bamboo carbohydrates for the production of the ethanol. Biotechnology and Bioengineering, 25:1071-1082, 1983. 